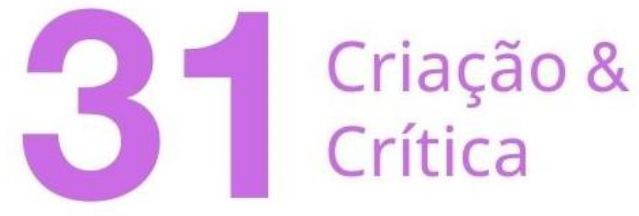

\section{OUVIDO-VOZ: UMA MÁQUINA}

Gustavo Rodrigues Penha ${ }^{1}$

RESUMO: Este artigo aborda a conexão entre ouvido e voz na construção de uma máquina perceptiva, selecionadora e preensora de linhas expressivas sonoras captadas auditivamente. Trata-se de uma etapa determinante no processo de audição, em que o aparelho vocal é acionado quando um sinal perceptivo se produz no ouvido, que é assim agitado ao se deparar com uma excitação material sonora exterior. Tal acionamento do aparelho fonador se dá instantaneamente à agitação do sinal perceptivo, funcionando de maneira complementar ao ouvido. Através de um cruzamento bibliográfico atento a alianças conceituais possíveis em uma ampla rede de textos, buscou-se conectar e colocar em ressonância autores literários, musicais e filosóficos que trataram direta ou indiretamente esse objeto de estudo, com o intuito de clarear alguns aspectos implicados na operação contínua de uma máquina ouvido-voz funcionando em diferentes modos de atividades perceptivas e criativas.

PaLAVRas-Chave: voz, ouvido, escuta, leitura, percepção, solfejo

ABSTRACT: This paper discusses the connection between ear and voice in the construction of a perceptual machine, which selects expressive sound lines audibly captured. This is a decisive step in the hearing process, in which the vocal apparatus is activated when a perceptual signal is produced in the ear, which is thus agitated when faced with an external sound material excitation. Such activation of the vocal tract is instantly given to the agitation of the perceptual signal, working in a complementary way to the ear. Through a literature review attentive to possible conceptual alliances in a wide network of texts, we sought to connect and resonate with literary, musical and philosophical authors who dealt directly or indirectly with this object of study, in order to clarify some aspects involved in the continuous operation of an ear-voice machine operating in different modes of perceptual and creative activities.

KEY-WORDS: voice, ear, listening, reading, perception, solfege

\footnotetext{
Gustavo Rodrigues Penha é bacharel em composição musical pela FASM, e mestre e doutor pela UNICAMP, sob orientação do Prof. Silvio Ferraz e com bolsa da FAPESP. Desde 2016 é professor da Universidade Federal de Mato Grosso do Sul - UFMS, onde desenvolve pesquisa com apoio do Conselho Nacional de Desenvolvimento Científico e Tecnológico - CNPq.
} 


\section{Criação \&}

Busca-se aqui nesse artigo abordar o problema do acoplamento entre voz e ouvido², da íntima relação entre ambos na atividade perceptiva e na produção de afetos e sentidos (linguísticos, musicais, artísticos). Trata-se de uma investigação atenta à percepção das sutilezas implicadas no funcionamento de uma máquina audiovocal que opera de maneira contínua entre os membros das comunidades de ouvintes ${ }^{3}$ em vigília, mas que não deixa de atravessar regiões de sonhos, hipnoses, transes ou estados de inconsciência ou de alteração de consciência nos membros dessa comunidade, nem sempre tão despertos ou sóbrios o suficiente.

Essa relação entre ouvido e voz implica um motor de funcionamento contínuo que faz com que a excitação do ouvido externo, por um sinal acústico, acione imediatamente o trato vocal do ouvinte, fazendo-o repetir vocalmente certas linhas expressivas apreendidas na audição, quer seja por uma vocalização tornada energia acústica, quer seja pela construção de uma imagem vocal mental, algo por vezes denominado subvocalização ${ }^{4}$. Maine de Biran (1766-1824), filósofo francês que trouxe algumas significativas contribuições para esse problema de uma conexão íntima entre voz e ouvido, especialmente em certos trechos de sua obra "De l'aperception immédiate" (2005[1807]), descreve tal fenômeno da seguinte maneira:

Com efeito, no mesmo instante em que uma agitação sonora atinge o ouvido externo, à reação motriz consecutiva, necessária para completar a sensação, se junta ainda uma determinação da mesma ordem, que vai ativar as teclas correspondentes do instrumento vocal: em virtude dessa determinação ativa, esse som direto repetido, imitado como que por eco, se redobra assim no sentido interno do ouvido e da voz, percutindo então, simultaneamente ou em um instante indivisível, duas impressões iguais mas distintas, uma sentida ou percebida como vinda de fora, e outra apercebida ou refletida como produto imediato do esforço ou da atividade da alma que a cria. (BIRAN, 2005[1807], 225-226)

A criação de uma imagem vocal virtual, ou o correspondente acionamento de teclas "do instrumento vocal" sem necessariamente se produzir uma imagem acústica, consiste então em uma etapa determinante no processo de escuta, funcionando de maneira complementar ao sinal perceptivo que se produz no ouvido quando agitado por se deparar com uma excitação material sonora exterior. Nesse processo, há

\footnotetext{
${ }^{2}$ Ao longo do século $X X$ e dessa primeira parte do século $X X I$, autores da ciência cognitiva também têm se ocupado em estudar alguns aspectos da coarticulação entre o trato vocal e o ouvido, havendo uma relevante literatura voltada, especialmente, ao processo de percepção da fala. Uma revisão crítica e abrangente de algumas das principais teorias desenvolvidas sobre o problema pode ser encontrada em FOWLER, GALANTUCCI \& TURVEY (2006).

${ }^{3}$ As complexas relações entre a máquina ouvido-voz e o funcionamento da linguagem na comunidade de surdos, mudos e surdos-mudos precisariam ser objeto de outros estudos específicos, não sendo possível abarcá-lo no presente artigo.

${ }^{4}$ Sobre o papel de subvocalização na percepção de imagens auditivas, ver SMITH, WILSON \& REISBERG (1995).
} 


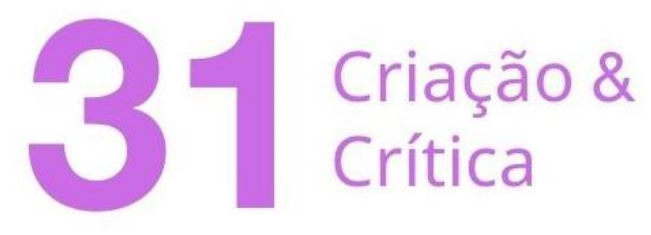

duas espécies de apercepções, próprias ao sentido do ouvido unido à voz: aquela relativa ao esforço vocal, considerado em sua livre determinação e que se distingue com o nome já reconhecido de apercepção imediata interna, e aquela que corresponde ao resultado desse esforço ou ao seu produto, que poderia ser chamado de apercepção mediata também interna. (BIRAN, 2005[1807], 227)

O esforço vocal se refere aqui a esse acionamento espontâneo e instantâneo de "teclas" do aparelho fonador a partir de um sinal perceptivo auditivo, que resulta em uma apercepção imediata. E complementarmente a esse esforço espontâneo, há o produto resultante desse acionamento de teclas do trato vocal, produto este já da ordem de uma apercepção mediata interna. Um paralelismo com a prática instrumental musical parece evidente nessa ideia de Biran de "acionamentos de teclas do instrumento vocal". Essa distinção - entre o esforço espontâneo que aciona "teclas" vocais e o produto desse acionamento - é importante na medida em que o resultado da apercepção mediata não pode ser compreendido como idêntico àquilo que foi experimentado na apercepção imediata, mas sim como produto de um filtro dinâmico, de capacidade mais ou menos limitada ou estendida de captação e repetição de linhas sonoras expressivas. Trata-se de uma distinção entre um produto formado e uma travessia por um processo que torna possível a formação desse produto, que se constrói pela repetição vocal de tais ou quais linhas apreendidas em uma audição. Assim, pelo fato de se formar a partir da seleção ${ }^{5}$, preensão ${ }^{6}$ e repetição de linhas expressivas captadas de um sinal perceptivo, o produto que caracteriza a apercepção mediata interna é por natureza um produto modificado, uma imagem sonora filtrada, deglutida e ruminada ${ }^{7}$.

A escuta auditiva ocorre, portanto, através do envolvimento mútuo de pelo menos dois meios distintos: o ouvido e a voz. É como se houvesse um curto-circuito entre voz e ouvido, de funcionamento muito sutil, e que de maneira alguma exclui a possibilidade de atuação simultânea de outros meios e sentidos corporais durante a escuta, visto o caráter polimodal ou multimodal próprio à percepção. Entretanto, vale ressaltar que na audição, ainda que diversos meios perceptivos possam ser incitados a entrar em atuação intensivamente em tal ou qual momento, tais meios funcionam sempre por acoplamento a esse par de intercâmbio dinâmico, voz-ouvido ${ }^{8}$. Ou seja, ao se tratar o acoplamento ouvido-voz como uma máquina, não se compreende o conceito de máquina exclusivamente no sentido de máquina tecnológica,

\footnotetext{
${ }^{5}$ Sobre a concepção de percepção como seleção, ver BERGSON 1999[1939].

${ }^{6}$ Ao longo do texto, optou-se pelo uso da ideia de "preensão" enquanto operadora de captação e aderência no processo perceptivo, ou seja, como "ato de segurar, agarrar ou apanhar" (CUNHA, 2007[1982], 630). Tal opção se justifica devido ao fato de o termo "apreensão" (mais comum em português e que em algumas situações funciona como sinônimo de "preensão") carregar um sentido de compreensão e entendimento, de clareza e distinção, que nem sempre está presente durante uma atividade perceptiva.

${ }^{7}$ Talvez não à toa se dê a louvação nieztcheana à ruminação: "É verdade que, para praticar a leitura como uma "arte", é necessário, antes de mais nada, possuir uma faculdade hoje muito esquecida [...], uma faculdade que exige qualidade bovinas e não as de uma homem moderno, ou seja, a ruminação."(NIETZSCHE, 2007[1887], 20).

8 "Esse desdobramento cristalino do real institui um "circuito interior" em que o atual e seu virtual não cessam de se intercambiar, de correr um atrás do outro, "distintos, mas indiscerníveis." (ZOURABICHVILLI, 2003, 22)
} 


\section{Criação \&}

mas sim de uma maneira mais ampla, enquanto modo de conexão de elementos e sistemas heterogêneos. A máquina, nessa concepção, é aberta ao exterior, e estabelece variados modos de relação com componentes orgânicos e sociais e subjetividades individuais ${ }^{9}$.

A subvocalização é um processo bastante conhecido na área da leitura, caracterizando-se pela criação de uma linha vocal mental pelo acionamento de nosso trato vocal durante a leitura de palavras e linhas de um texto. A leitura implica assim uma recriação vocal do texto, tal como a audição implica uma recriação vocal daquilo que se ouve. E se tal operação audiovocal participa, nas comunidades de ouvintes, dos processos de produção de sentido disparados pela linguagem falada e escrita, o processo de escuta musical também se serve de tal máquina para acontecer. "A audição também é um ato: ouvir uma palavra, é articulá-la interiormente, ouvir um som, é cantá-lo interiormente, compreender a música, é recriá-la. » (BRELET, 1949, 410). Assim, ouvir uma música implica uma atuação que se dá, em parte, pela repetição vocal de linhas sonoras preendidas pela audição.

Há quem afirme que a voz é o elemento que tornou possível a emancipação disso a que convencionamos chamar de som. É o caso da musicóloga francesa Gisèle Brelet, que afirma que "o som, origem da música, só pôde existir realmente graças à voz, que lhe libera dos objetos que o mantinham aprisionado para lhe fazer conquistar a pureza de sua natureza. A voz, parente do som, ao produzi-lo, fez com que este se tornasse si mesmo" (BRELET, 1949, 400)". Chega-se assim a uma tendência de certa forma concretista da voz, que deixa de ser pensada somente nas suas funções de canto, ou de fala, para ser tratada enquanto "antena" e sistema de sucção de linhas sonoras, emitidas por objetos físicos os mais distintos.

Aqui há, talvez, uma significativa modificação na concepção da conexão voz-ouvido como operadora de um sistema de processamento de fluxo sonoro do tipo fora-dentro, ou de um sistema de dobras. Se o senso-comum indica a voz como meio expressivo de exteriorização de uma interioridade e o ouvido como meio de interiorização dos sons do mundo, essa outra lógica, concreta, parece torcer essas relações. Em acoplamento com a voz, o ouvido se direciona ao interior não para nele injetar os sons do mundo, mas sim para acionar o instrumento vocal que, por sua vez, se projeta para fora, entrando nas coisas para delas extrair seus sons, suas próprias vozes. O ouvido busca internamente um modo de se projetar para fora acionando a voz que, por sua vez, se lança ao exterior visando extrair o dentro do fora ${ }^{10}$. Mas vale ressaltar que o funcionamento por cristalização entre voz e ouvido faz com que frequentemente seja indiscernível aquilo que cada órgão ou sentido produz individualmente no decorrer de uma percepção. Assim, é toda a máquina que se dirige ao fora para dele the extrair o seu dentro.

\footnotetext{
${ }^{9}$ Sobre o conceito de máquina, ver: DELEUZE, GUATTARI, 2010 [1972/1973], 54-61; DELEUZE, GUATTARI, 1995a, 1995b, 1996, 1997a, 1997b [1980]; GUATTARI, 2013[1990], 111-129

10 "Precisamos que a expressão, aqui, nada tem a ver com um processo de exteriorização a partir do dentro. É, sobretudo, o contrário disto. A concepção deleuziana da subjetividade repousa sobre a ideia de um dentro do fora, de uma interiorização do exterior, no duplo sentido do genitivo (não há interioridade pressuposta: não se deve perder de vista a repetição à distância, que é aquilo em que consiste o envolvimento)." (ZOURABICHVILLI, 2016[2004], 112-113)
} 


\section{Criação \&}

Durante as décadas de 1950 e 1960, o compositor e engenheiro Pierre Schaeffer, fundador do Groupe de Recherche Musical (GRM), desenvolveu uma concepção fenomenológica da escuta que tem como principais pilares os conceitos de objeto sonoro e de escuta reduzida. Na concepção fenomenológica de Schaeffer a intenção de escutar/entender [intention d'entendre] aparece como um importante fator para o funcionamento da escuta reduzida. A escuta reduzida se caracteriza por ser uma atitude de escuta, uma postura, uma atividade que, não sem uma carga de cientificidade, isola os sons para melhor analisá-los e descrevê-los a partir de critérios tipo-morfológicos compreendidos enquanto propriedades dos objetos sonoros percebidos, e não simplesmente enquanto propriedades mensuráveis do sinal sonoro físico (SCHAEFFER, 1966, 501). Os critérios tipomorfológicos evidenciados por Schaeffer buscam objetivar modos de perceber as qualidades e potências de comportamentos e linhas de variações através de escalonamentos de aspectos energéticos implicados nos sons. É então pela criação de escalas de valores qualitativos que indicam variáveis de durações, intensidades e alturas em suas correspondentes localizações e calibres nas dimensões percepto-auditivas que os critérios tipo-morfológicos se definem. Tais escalas, que não deixam de servir como mensurações, não tomam como base valores absolutos que têm por referência alguma medida extensiva provinda da física acústica (em milissegundos, decibéis ou Hertz), mas se efetuam por uma método que determina algumas séries, contínua ou discretamente, de traços distintivos dos sons percebidos auditivamente e isolados de seus históricos energéticos próprios. Assim, para a escuta reduzida é necessário uma intenção ${ }^{11}$ de analisar e descrever o que acontece qualitativamente nos sons, não bastando extrair medidas e grandezas físico-acústicas que Ihes são correspondentes sob determinados pontos de observação parcial. E para a tomada de consciência acerca da preensão das qualidades e variações energéticas implicadas nos critérios tipo-morfológicos, desenvolve-se todo um treinamento de um solfejo concreto que tem na voz uma importantíssima ferramenta de sintonização e preensão de nuanças e diferenças sonoras, ainda que Schaeffer não aborde esse sutil fenômeno perceptivo audiovocal implicado na escuta, por não ter the dado uma atenção direta.

Esse conceito prático de escuta reduzida é criado por Schaeffer juntamente a uma distinção com outros dois modos de escuta: a escuta natural, ligada a um instinto primitivo de sobrevivência e que nos faz rapidamente distinguir e identificar uma fonte sonora em um evento sonoro, até para saber o quão urgente se lhe é necessário dirigir a atenção, por sua proximidade ou perigo ${ }^{12}$ ("O que é isso? O que aconteceu?" (SCHAEFFER, 1966, 114)); e a

\footnotetext{
11 "Esta intenção de entender deve se comunicar e se definir através da criação de uma "terminologia adequada" que Pierre Schaeffer chama de uma metalinguagem." (CHION, 1983, 144)

12 Bergson também aborda a questão da urgência de atenção na atividade perceptiva, da seguinte maneira: "É preciso [...] compreender de fato que a necessidade da afecção decorre da própria percepção. A percepção, tal como a entendemos, mede nossa ação possível sobre as coisas e por isso, inversamente, a ação possível das coisas sobre nós. Quanto maior a capacidade de agir do corpo (simbolizada por uma complicação superior do sistema nervoso), mais vasto o campo que a percepção abrange. A distância que separa nosso corpo de um objeto percebido mede portanto efetivamente a maior ou menor iminência de um perigo, o prazo maior ou menor de uma promessa. $E$, por consequência, nossa percepção de um objeto distinto do nosso corpo, separado de nosso corpo por um intervalo, nunca exprime mais do que uma ação virtual. Porém, quanto mais diminui a distância entre esse objeto e nosso corpo, tanto mais o perigo torna-se urgente ou a promessa imediata, tanto mais a ação virtual tende a se transformar em ação real. Passemos agora ao limite, suponhamos que
} 


\section{Criação \&}

escuta cultural, em que se busca retirar uma mensagem, uma significação ou alguns valores a partir de uma agitação sonora, abstraindo tal mensagem do próprio evento sonoro. Na teoria schaefferiana a escuta natural corresponderia à categoria do escutar [écouter], e a escuta cultural à do compreender [compreendre], enquanto a escuta reduzida, melhor exercitada por meio da prática do solfejo do objeto sonoro, corresponderia a aprender a escutar/entender [entendre] por meio da qualificação de certas linhas expressivas selecionadas pelo ouvido, qualificação essa que compreende a aquisição de todo um vocabulário analítico derivado das variações tipo-morfológicas. Entretanto, ao abordar os diferentes modos de escuta que propõe em sua teoria, Schaeffer não observa o relevante papel da voz no funcionamento da percepção auditiva, concebendo-a ainda somente como uma fonte sonora ou como linha individual de uma trama polifônica ${ }^{13}$.

O canto dos pássaros ocupa uma parte variável na atenção auditiva do senhor Palomar: ora ele se afasta com um componente do silêncio de fundo, ora se concentra como que distinguindo-os trinado por trinado, reagrupando-os em categorias de complexidade crescente: chilreios puntiformes, trilados de duas notas, uma breve uma longa, trucilares curtos e vibráteis, chamarizes, cascatas de notas que veem em escala decrescente e se interrompem, caracóis de modulações que se curvam sobre si mesmas, e assim por diante até chegar aos gorjeios. (CALVINO, 2010[1983], 24-25)

Também na audição de sons cotidianos, mais ou menos harmônicos ou ruidosos, a engrenagem ouvido-voz funciona acionando, de maneira imediata no instrumento vocal, alguns equivalentes fonéticos extraíveis do sinal sonoro percebido, e produzindo, por consequência, alguma imagem vocal acústica ou mental que destaca tais ou quais linhas sonoras expressivas extraídas nesse processo. "A voz liberou e efetivamente criou o som arrancando-o das coisas". (BRELET, 1949, 402)

Nesse trecho acima, de Palomar, ainda que Ítalo Calvino (2010[1983]) não descreva especificamente uma repetição vocal decorrente de uma audição atenta, é possível sentir que as qualificações verbais dos cantos dos pássaros só puderam realmente se efetivar por meio de uma repetição vocal minuciosa de elementos sutis, que dão vida e constroem o drama de

a distância se torne nula, ou seja, que o objeto a perceber coincida com nosso corpo, enfim, que nosso próprio corpo seja o objeto a perceber. Então não é mais uma ação virtual, mas uma ação real que essa percepção muito particular irá exprimir: a afecção consiste exatamente nisso. Nossas sensações estão, portanto, para nossas percepções assim como a ação de nosso corpo está para a ação possível ou virtual". (BERGSON, 1999[1896], 58-59)

${ }^{13}$ Ao se procurar as diferentes entradas da palavra voz [voix] no Traité (1966, pp. 42, 47, 54, 60, 61, $66,67,72,79,83,85,87,88,89,90,91,105,106,108,110,124,132,151,162,163,207,270,286$, $292,309,310,311,312,317,323,325,326,334,341,342,394,396,431,448,458,490,506,511$, $512,550,552,573,574,629,637,638,653,670,685,699,703)$, não se encontra qualquer referência da ideia da voz acoplada ao ouvido e participando dos diferentes processos de escuta. Talvez até pelo fato de Schaeffer não ter atribuído uma importância à voz no processo de escuta, que Chion não tenha destacado a voz como um conceito de destaque na teoria schaefferiana em seu Guia. 


\section{Criação \&}

cada canto de pássaro individual. É quase possível ver o Senhor Palomar cantarolando junto aos pássaros na sua viva atividade de escuta, diretamente conectada à sua incessante e insaciável curiosidade por conhecer o mundo.

Nem toda escuta, musical ou discursiva, é analítica. E nem toda análise implica a escuta. Entretanto, para que aconteça uma escuta (auditiva) que implique análise, faz-se então necessária a participação da voz na construção de imagens vocais potencialmente analisáveis, bem como na seleção e extração de evoluções energéticas nas linhas sonoras. Nesse fino processo de escuta e de preensibilidade de variações energéticas em um som, a voz é que torna possível o surgimento de uma análise auditiva, ao selecionar e captar certas linhas para, só então, repeti-las à distância, direcionando um foco de atenção que atende a uma motivação atual.

Não se trata de afirmar que um evento sonoro é todo decomposto em traços vocais no momento da escuta, mas antes, sim, de afirmar que a voz realiza uma atividade de seleção e preensão ao encontrar equivalências fonéticas implicadas em certas linhas sonoras, de acordo com relações possíveis de se estabelecer entre os elementos constituintes da vida interna de um som e certos fonemas ou configurações do aparelho fonador, do ponto de vista da distribuição dos parciais e de suas evoluções dinâmicas no tempo. Entretanto, os modos de acionamento de "teclas" desse instrumento vocal virtual não são de maneira alguma uniformes e dados como prontos de antemão. Pelo contrário, esses modos de acionamento estão condicionados a uma capacidade de afetar e ser afetado própria a tal ou qual máquina ouvido-voz ${ }^{14}$. E tal capacidade de afetar e ser afetado é natural, histórica e socialmente construída, por meio da experimentação de solfejos os mais diversos ${ }^{15}$. É nesse sentido que se pode afirmar que não há nunca um solfejo de segunda mão. Todo solfejo, por mais imitativo que seja, engendra suas próprias ranhuras em uma máquina audiovocal apreendedora de mais ou menos nuanças e diferenças, conforme sua capacidade dinâmica de afetar e ser afetada.

Assim, trabalhar o ouvido, desenvolver a escuta, são atividades que implicam um trabalho de seleção e preensão exploratória de sutilezas fonéticas com as quais é possível acompanhar aquilo que, auditivamente, possui evolução de ordem linear e diacrônica, por mais contínua ou fragmentada que seja essa evolução ou história energética ${ }^{16}$. "[Um ouvinte] treina seu ouvido assim como o outro [o músico] pratica seu instrumento" (SCHAEFFER, 1966, 341); com o acréscimo de que esse treinamento auditivo implica necessariamente uma exploração do aparelho fonador a partir da qual se aumenta as capacidades audiovocais do ouvinte-solfejista. Ou seja, é somente por experimentação e prática que a potência de afetar e ser afetada de uma máquina audivocal se desenvolve e torna possível a preensão e (re)criação de novos mundos sonoros.

\footnotetext{
${ }^{14}$ Sobre a potência de afetar e ser afetado no pensamento de Espinosa, ver DELEUZE, 2002[1981].

${ }^{15}$ Sobre o conceito de solfejo, em uma concepção polissêmica e mais condizente com os dias atuais, ver PENHA, 2016, pp. 75-152.

${ }^{16}$ Sobre a ideia de evolução energética ou história energética de um som, ver: SCHAEFFER, 1966, 198, 224-225, 238, 432, 548; e FERRAZ, 2018[2005], 59-63.
} 


\section{Criação \&}

Há, contínuo, aqui ou acolá, um gluglu, um chupão líquido, água rolando n'água; lá embaixo, nas pedras, a corredeira se apressa ou amaina; mas o som nunca é o mesmo de dois instantes atrás. (GUIMARÃES ROSA, 2001[1946], 229)

Nessa passagem do conto Minha Gente, presente no livro Sagarana, de João Guimarães Rosa, há alguns elementos a ser destacados: uma escrita que faz com que se sinta articulatoriamente o próprio fluxo de uma corrente de água ("contínuo, aqui ou acolá", "água rolando n'água"); o "gluglu", enquanto onomatopeia que também colabora na sensação de movimento de água; o "chupão líquido" que, assim como o gluglu, só pode ser retirado da sonoridade da corrente de água ao se colocar a voz dentro do riacho; e, por fim, a ideia de uma contínua produção sonora, mas também em uma incessante preensão, captadora de nuanças e diferenças manifestas pelo som.

Não se sabe de antemão quais afetos são disparados nessa seleção e preensão de linhas expressivas sonoras pela máquina ouvido-voz. Se, por um lado, há um funcionamento mais duro das produções de afetos ligadas às relações estabelecidas e catalogadas entre materiais sensíveis e determinados afetos que lhes sejam correspondentes (os chamados clichês), há também toda uma abertura a nuanças e diferenças transitórias, experimentais e inaugurais. A audição e repetição vocal de certas linhas participam dos disparos de afetos dos mais previsíveis aos mais inusitados, e carregam consigo traços da materialidade sonora preendida pela voz durante uma percepção auditiva.

Por que é tão difícil ouvir aquela música que nos parece insuportável? O que acontece é que, ouvindo-a, depositamos um esforço significativo na repetição vocal de algo que não condiz com nosso gosto pessoal e que somos como que forçados a deglutir. Não é à toa que a música sempre esteve tão intimamente ligada com os gostos pessoais, pois ela também se serve da língua para a preensibilidade de materalidades perceptivas disparadoras de acontecimentos afetivos. Também a crescente sensação de insuportabilidade que se vivencia ao se ouvir um choro de bebê é decorrente dessa operação de solfejar um choro que a máquina voz-ouvido nos força a fazer sentir a cada instante. Durante o choro do bebê acessamos certas teclas fisiológicas em nosso aparelho fonador, que por sua vez disparam linhas afetivas, fazendo-nos também sentir, em uma ressonância por simpatia, uma necessidade primordial de alimento, calor, colo ou higiene. É daí que vêm a sensação de urgência de se atender a necessidade de um bebê, talvez primitivamente mais conectada a uma manifestação direta de uma força a perseverar no próprio ser ${ }^{17}$ do que, efetivamente, a um altruísmo em prol do bebê, ainda que tal força tenha se intensificado por simpatia a partir do choro.

O teórico musical Arnie Cox $(2001 ; 2011)$ é um dos autores recentes que aborda o fenômeno da subvocalização intencional ou instantânea na escuta do ponto de vista da

17 Sobre o esforço a perseverar no seu ser, ver: ESPINOSA, 1989[1677], em especial Livro III, Proposições VI-IX (pp. 116-117). 


\section{Criação \&}

cognição musical. Entretanto, sua abordagem está interessada em saber como os humanos compreendem os sons, considerando a subvocalização em um processo mimético, como uma forma de imitação vocal de uma forma sonora pronta. Com base em autores da Motor Theory, bem como outros autores da cognição linguística, Cox constrói uma teoria atenta ao acionamento motor do aparelho vocal durante a escuta, mas ainda se mantém por demais preso ao modelo da recognição, o que é possível exemplificar em sua concepção um tanto quanto tradicional de timbre, excessivamente preso à fonte de produção sonora. A distinção e identificação de uma fonte sonora instrumental, ainda que seja uma etapa significativa do processo de escuta, diz muito pouco, ou quase nada, sobre a história energética e os modos de variação timbrística dos sons, que podem ser microscopicamente observados e sentidos pela potência analítica e sintética da repetição vocal.

Não à toa, uma boa parte da terminologia e vocabulário de procedimentos e operadores musicais está em direta relação com estudos sobre línguas, discursos e orações (frase, período, acento, articulação, retórica, gramática, sintaxe, etc.). Além disso, boa parte das diferenciações entre os períodos históricos na música ocidental se determina justamente pelos diferentes modos de conceber a relação texto e música em uma composição musical. No período renascentista, as vozes entravam em acordo (produzindo o que veio a ser chamado um acorde) ao cadenciar na finalização dos versos. No barroco, trata-se de ilustrar afetivamente a palavra, de produzir quadros, ora pequenos ora maiores, a partir de relações diretas entre texto e certos materiais musicais. Há, efetivamente, todo um vocabulário e um catálogo de relações diretas entre materiais musicais e seus correspondentes afetos disparáveis e evocáveis. O classicismo é talvez o período que mais objetivou uma total autonomia da música com relação ao texto linguístico, com a condição de se construir sobre o suporte de toda uma gramática e sintaxe historicamente estabelecidas. No romantismo, o próprio problema da oposição entre música absoluta e música programática passa por uma relação de aceitação ou não de uma relação direta com imagens textuais. Já nos séculos XX e XXI, a relação entre música e texto se moleculariza foneticamente para produzir novas conexões potencialmente fecundas aos pensamentos musical e poético.

Entretanto, nos repertórios de diferentes povos e épocas, há um operador que maquina certos aspectos do pensamento musical e que está em direta relação com a voz, trata-se do fraseado. Em uma definição parcialmente bastante feliz de fraseado, o compositor, regente e musicólogo belga André Souris $(1976,260)$ afirma:

[o fraseado] é o conjunto de meios à disposição na execução para tornar sensíveis a estrutura da frase, suas divisões, suas ligações, suas trajetórias, suas flutuações dinâmicas, suas modificações de velocidade, e enfim a articulação e os modos de ataque de cada um dos sons que a compõem. A arte do fraseado consiste também em fazer valer as oposições das frases entre elas, suas relações recíprocas e o papel que elas exercem na configuração total do trecho. Tende-se a esquecer que a frase, cantada ou tocada sobre algum instrumento, preexiste à notação e à análise musical, assim como a frase falada preexiste à escrita e à gramática. [...] Ela é o fato 


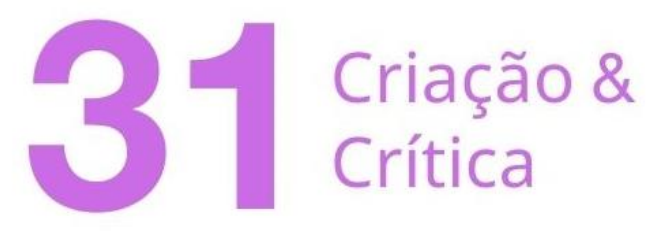

musical original, o princípio de unidade da forma sonora. O fraseado é então a atividade musical por excelência, à qual se refere toda notação. Mas nenhum sistema de signos lhe pode dar a ideia, cada notação comporta índices mais ou menos numerosos do traçado da frase, nunca a equivalência de suas ligações orgânicas, nem de seu sentido.

Há, talvez, somente um ponto a se tomar com ressalva neste trecho da definição de Souris, que diz respeito a uma interpretação possível que dê ao fraseado uma existência anterior à sua efetuação corporal. Se há uma real independência do fraseado com relação a uma realização sonora qualquer, justamente pelo fato de o fraseado ser da ordem do acontecimento e como tal não se confundir com as efetuações corporais, isso não quer dizer que ele é anterior a sua encarnação. Teria sido mais preciso se Souris dissesse que uma realização instrumental ou vocal implica um fraseado, com o qual se envolve mutuamente (se complica). O fraseado funcionaria assim como uma máquina abstrata, com o destaque de que tal "máquina abstrata não existe mais independentemente do agenciamento, assim como o agenciamento não funciona independentemente da máquina." (DELEUZE, GUATTARI, 1995b[1980], 45)

$\mathrm{Na}$ definição de Souris, o fraseado, enquanto "atividade musical por excelência", funciona conectando os elementos sonoros e articulatórios e conduzindo linearmente os dramas implicados nas frases. Trata-se de um operador de sutilezas e nuanças implicado em todo fluxo sonoro, assim como em toda prática vocal, instrumental ou eletrônica. Não se fala aqui, entretanto, o fraseado, no singular e com artigo definido, mas somente com um artigo indefinido, um fraseado, enquanto um modo de conexão e condução dos diferentes elementos implicados em uma frase, ou no plural, os fraseados, numa atenção à riqueza da variedade de modos de conexão e condução. $E$ a ideia de "atividade musical por excelência" de Souris ressoa ainda com uma outra afirmação de Gisèle Brelet (1951, 239), para quem "o gesto musical por excelência é o gesto vocal". Um tal conceito de gesto vocalé compreendido enquanto

aquilo que, por suas próprias forças e sem o socorro de um instrumento, é capaz de produzir as sonoridades, que o ouvido recolhe e que a inteligência contempla. O gesto vocal parece estabelecer uma transição e uma ligação entre os gestos visíveis e ainda profundamente engajados na matéria que são os gestos do corpo, e a atividade secreta e invisível de um eu [moi]. O gesto vocal escapa a toda manifestação visível: e somente se traduz pelos sons. (BRELET, 1951, 237)

Talvez o acoplamento ouvido-voz funcione como um ponto de bifurcação (ou de ramificação) pelo qual acontecem os processos de produção de sentido disparados por um sinal auditivo. Essa bifurcação faz com que, de um lado, ocorram produções de sentido linguísticos; e de outro, produções de sentido musicais. Esses dois modos de produção de 


\section{Criação \&}

sentido não se excluem um ao outro, pelo contrário, há envolvimento mútuo e contínuo entre música e linguagem, tanto na escuta de obras musicais ou quanto na leitura de obras literárias ou filosóficas. E é a partir de e com essas linhas bifurcadas, que poesia e canção se produzem, fazendo entrelaçar, com voltas, nós e emaranhados os mais variados, as pontas soltas dessas duas linhas bifurcadas. As linhas são distintas, mas indiscerníveis nesses entrelaçamentos que põem em funcionamento máquinas poéticas e musicais. "Na linguagem, a palavra reveste uma significação prática e abstrata, sem relação com as qualidades sonoras: o som lhe é assim dissociado de seu sentido propriamente sonoro que a poesia e a música, cada uma a sua maneira, Ihe restituem." (BRELET, 1949, 410-411).

Um perfil melódico, um comportamento rítmico, um funcionamento articulatório, uma distribuição do conteúdo espectral - elementos sonoros com os quais o pensamento musical produz toda uma variedade de imagens em relação - estão implicados nas frases e nas palavras linguísticas, seja quando lidas em voz alta ou mentalmente. Assim, o complexo processo de produção de sentido disparado por signos linguísticos acontece em cruzamento constante com imagens sonoras potencialmente musicais ou musicáveis. É como se houvesse uma dimensão musical latente em todo enunciado linguístico, que pode ser diferentemente percorrida, acentuada ou exagerada a cada nova repetição vocal do enunciado, a cada nova encarnação audiovocal do texto.

Não somente poesia ou a canção lidam com o problema das ritmicidades motívicas e estilísticas potencialmente operacionais em um texto linguístico. A prosa, a filosofia e a escrita textual de maneira geral também podem se servir de tais jogos de durações e saliências para produzir estilos textuais e audiovocais distintos:

A filosofia mobiliza e trata de conceitos. É normal que haja a vocalização dos conceitos numa aula, assim como há um estilo de conceitos por escrito. Os filósofos não escrevem sem elaborar um estilo. São como artistas, são artistas. Uma aula implica vocalizações, implica até uma espécie de [...] Sprechgesang. Evidentemente. [...] Desde o primário é assim. O mais importante é a relação entre a voz e o conceito. (DELEUZE, 1996)

Acerca da questão do estilo na escrita ${ }^{18}$, Deleuze chega mesmo a afirmar que o estilo é puramente auditivo. Uma tal afirmação aponta justamente para um funcionamento de um motor rítmico sobre os fonemas, palavras e frases constituintes dos textos, indicando a presença de volteios, motivos, saliências, variações e contrapontos não somente conceituais, mas principalmente fonético-articulatórios. Na escrita textual, o estilo funciona como um produtor de ritmicidades auditivas, formando saliências e dobras pelas quais surfam e mergulham as leituras. Se ter um estilo, em literatura (mas também em filosofia e em outras atividades de escrita), consiste em fazer gaguejar a própria língua (DELEUZE, 1997[1993], 138-146) significa também ser capaz de produzir relevos rítmico-articulatórios produtores de motivos sonoros, auditivos e gestuais que evidenciam o caráter de desequilíbrio perpétuo dos

\footnotetext{
${ }^{18}$ Acerca do conceito de estilo em Deleuze, vale destacar três textos publicados em língua portuguesa escritos por competentíssimas pesquisadoras do pensamento deleuziano: COSTA MALUFE, 2010; GODINHO, 2007; e SAUVAGNARGUES, 2010.
} 


\section{Criação \&}

sistemas linguísticos, levando-a a atingir seu limite (musical) (DELEUZE, 1996). Ler seria então um surfar ${ }^{19}$, um se deixar levar por fluxos de reentrâncias rítmicas. Nesse sentido, não se concebe aquela imagem do leitor intérprete e desvelador das verdades e dos segredos do mundo, mas sim um leitor dinâmico e desejante, à espreita ${ }^{20}$ de produções de sentido disparadas a partir das resistências e das porosidades sonoras-textuais implicadas na materialidade fonético-articulatória de frases e palavras.

Eu ouço e escrevo esses textos como músicas. São espécies de variações sobre temas que eu destruo progressivamente e que nunca se (re)conhecerá quando o texto está finalizado. Eu trabalho a partir de algumas palavras ou de uma pequena frase.

Eu escuto a voz das pessoas. A maneira como ela é colocada, se ela é tensa, suave, etc. Escuto bastante o vocabulário, a sintaxe, os sotaques, a pronúncia, o ritmo, a velocidade. Sou muito sensível aos dialetos, às expressões, às palavras postas diferentemente em uma frase, coloridas de uma certa maneira por um sotaque. São elementos ligados aos hábitos, ao entorno, à região, à vida. Eu me sirvo bastante de tudo o que ouço para escrever esses textos e lhe dar uma forma.

$\mathrm{Na}$ literatura também, 0 ritmo das frases me interessa demasiadamente. Em Flaubert, em Joyce que altera a invenção pura e a narração, em Beckett em que a escrita é uma música permanente, feita de minúsculas e infinitas variações.

Assim que terminados, leio meus textos em voz alta. Recitando-os, eu Ihes sinto e posso modifica-los. É comparável à prática de um instrumento. (APERGHIS,1990, 90.)

Nessa passagem, Aperghis evidencia que a leitura recitada em voz alta, que destaca certas nuanças do texto linguístico, faz com que o processo de seleção e escolha de materiais e de modos de variação textuais-sonoros ocorra por uma atividade que busca saborear e mergulhar nas sensações fonético-articulatórias das palavras do texto. "Cada palavra é uma obra poética” (BORGES, 2011[1995], p. 162). Assim, há toda uma prática experimental de ação da língua, da boca e de todo o aparelho fonador em função dos efeitos perceptivos sonoros produzidos, que podem ser variados de acordo com motivações composicionais locais ou globais. "O pensamento musical é especulação se exercendo imediatamente sobre o próprio som” (BRELET, 1949, 410-411).

Há certas obras musicais, literárias ou filosóficas em que se evidencia uma especulação acerca da possibilidade de fazer as linhas disjuntas bifurcadas em linguagem e música se incluírem e se envolverem mutuamente nos processos de produção de sentido.

\footnotetext{
${ }^{19}$ Sobre algumas relações entre o surfar e o pensamento deleuziano, ver LINS, 2008, 53-75.

${ }^{20}$ Sobre o estar à espreita no pensamento deleuziano, ver: ORLANDI, 2018, 395-417.
} 


\section{Criação \&}

Um exemplo desse tipo ocorre em Aventures e Nouvelles Aventures, peças escritas para cantores e grupo instrumental, em que Ligeti deixa claro que esteve muito atento à íntima relação entre música e linguagem na atividade perceptiva durante o processo composicional. Em um de seus relatos sobre as obras, o compositor afirma que

As peças musicais fonético-dramáticas Aventures e Nouvelles Aventures constituem um novo gênero artístico na medida em que texto, música e ação cênica nelas se fusionam totalmente para formar uma estrutura composicional única. Aqui, não há texto portador de significações que seriam em seguida "musicados". No entanto, há um "texto" fonético-musical que não pertence a uma língua humana precisa e também não é derivado da transformação ou da manipulação de uma língua. Esse "texto" é desprovido de todo sentido semântico, mas possui, por outro lado, um pronunciado sentido afetivo: partindo da camada sonora expressiva primordial das emissões sonoras produzidas pelos seres humanos, uma composição sonora autônoma foi desenvolvida. A composição musical propriamente dita e a composição fonética constituem uma unidade: 0 texto é feito pelo intermédio da música e a música pelo do texto. As partes instrumentais não "acompanham" as partes vocais, os instrumentos são tratados de maneira a completar e destacar as emissões sonoras humanas: a composição fonética se intromete até na composição sonora instrumental. (LIGETI, 2013[1966], 194)

Chega-se então nessas zonas de indiscernibilidade entre música e linguagem, entre ouvido e voz, entre música e poesia, entre voz e instrumento, que talvez possam nos conduzir ao destaque relevante que Borges faz a "uma coisa que temos dificuldade para admitir: o conceito de que a linguagem é um fato estético." (BORGES, 2011[1995],161)

O fato estético é algo tão evidente, tão imediato, tão indefinível, quanto o amor, o sabor da fruta, a água. Sentimos a poesia como sentimos a proximidade de uma mulher, ou sentimos uma montanha ou uma baía. Se a sentimos imediatamente, para que diluí-la em outras palavras, que sem dúvida serão menos marcantes que nossos sentimentos? (BORGES, 2011[1995], 166)

\section{Considerações finais}

Nesse artigo, buscou-se abordar diferentes pontos de vista sobre o problema de uma conexão íntima entre voz e ouvido, que funciona por meio de um curto-circuito cristalino infinito, apreensor de diferenças, nuanças e saliências. Ouvimos, solfejamos e ressolfejamos as agitações sonoras que acontecem em nós, seja para o simples reconhecimento da fonte, seja para analisarmos alguns aspectos próprios às vidas internas dos sons, a suas histórias ou evoluções energéticas. Assim, há, portanto, uma síntese vocal que funciona como 


\section{Criação \&}

condição de possibilidade de uma análise auditiva. E é dupla a natureza dessa síntese vocal: enquanto diretamente relacionada à percepção, ela é redutora, necessariamente selecionadora e captadora de linhas expressivas potencialmente repetíveis; e enquanto voltada à ação, ela é condutora, motor, de uma linha mais ou menos quebradiça de pensamento linear, seja musical ou linguístico. A síntese, enquanto tal, ocorre no imediato acionamento de "teclas de instrumento vocal" a partir de uma agitação sonora auditiva, se configurando então como uma apercepção imediata; já o produto da repetição vocal, acústica ou mental, resultante do processo, apresenta-se, uma vez formado, como uma apercepção mediata.

A cadeia sensório-motora implicada na conexão voz-ouvido funciona com a voz repetindo imediatamente certas linhas expressivas preendidas auditivamente pelo ouvido. É a partir dessa repetição, em que a voz necessariamente seleciona e apreende certas linhas acústico-articulatórias em detrimento doutras, que um sentido se produz, ou seja: um acontecimento irrompe a cadeia sensório motora, disjuntando percepção e ação, e implicando, assim o afeto no seio da produção de sentido.

Em trabalho anterior (PENHA, 2019), o processo de produção de afetos foi abordado enquanto um acontecimento disparador de uma intensa travessia, de uma passagem entre estados afetivos distintos, uma transição que, no escoamento de uma duração, produz aumento ou diminuição da potência de existir, pensar, de afetar e ser afetado. Talvez seja o caso de acrescentar, no presente artigo, que quando um acontecimento é deflagrado por signos auditivos (acústicos ou mentais), há um correspondente processo de produção de uma imagem vocal cristalina de, ao menos, duas faces: uma face, de acionamento imediato, virada à captação e seleção de perceptos constitutivos das imagens sonoras ou objetos sonoros; e outra face, de repetição mediata, caracterizada pela formação de uma imagem vocal portadora de certas linhas expressivas emitidas pelos objetos sonoros e condicionada a uma capacidade mais ou menos flexível de emissão vocal.

A tomada de consciência acerca do funcionamento dessa máquina ouvido-voz torna possível a emergência de uma série de problemas composicionais potencialmente exploráveis na criação musical, literária, filosófica e textual, dentre os quais, exemplifica-se: Quais vocalidades estão implicadas em tal ou qual frase musical e/ou linguística? Quais ritmicidades podem ser exploradas a partir de tal ou qual traço vocal? Como conduzir, provocar ou agitar o processo de escuta ou leitura a partir da atenção à disparação e ao acionamento do "instrumento vocal" quando do encontro do ouvido com linhas musicais, sonoras e linguísticas? Como operar com a variedade de afetos, inumanos até, decorrente da exploração de vocalidades mais ou menos harmônicas ou ruidosas?

Haveria ainda de se pensar o desdobramento do funcionamento dessa máquina ouvido-voz nos processos de ensino e aprendizagem, em especial naqueles voltados à música e à linguagem, com destaque a uma atenção a esse intervalo entre uma apercepção imediata e uma apercepção mediata e as potencialidades e operações fonético-articulatórias que Ihe são implicadas: Como desenvolver as capacidades vocais a ponto de potencializar o encontro com toda uma variedade de modos de emissão vocal resultantes do processo de vocalização ou subvocalização na escuta e na leitura, enquanto apercepção mediata? Pode o desenvolvimento das capacidades vocais tornar possível, como que por feedback, o acionamento de regiões ainda não exploradas do instrumento vocal já na apercepção imediata operante na escuta? Como são forjados e engendrados os filtros que selecionam e 


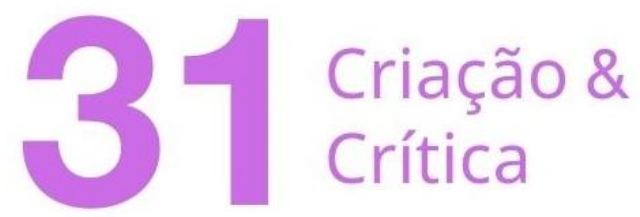

apreendem, pela voz, tais ou quais linhas expressivas presentes nos sons das coisas? Como, a partir da exploração vocal, incentivar e conduzir a extração de vocalidades presentes nos sons os mais diversos das falas, dos cantos, das palavras e das coisas?

Atuando na escuta, a voz e o aparelho fonador se apresentam, assim, como uma região de interconexão de diferentes modos de perceber, sentir, pensar, vociferar, respirar e cantar, participando de sensações que transitam entre matéria e memória e linguagem, entre inteligível e ininteligível, entre o claro e distinto e o sombrio e obscuro. Os poetas, as poetas, enquanto ouvintes à espreita e admiráveis ritmadores vocais, a seus modos, há tempos já o dizem:

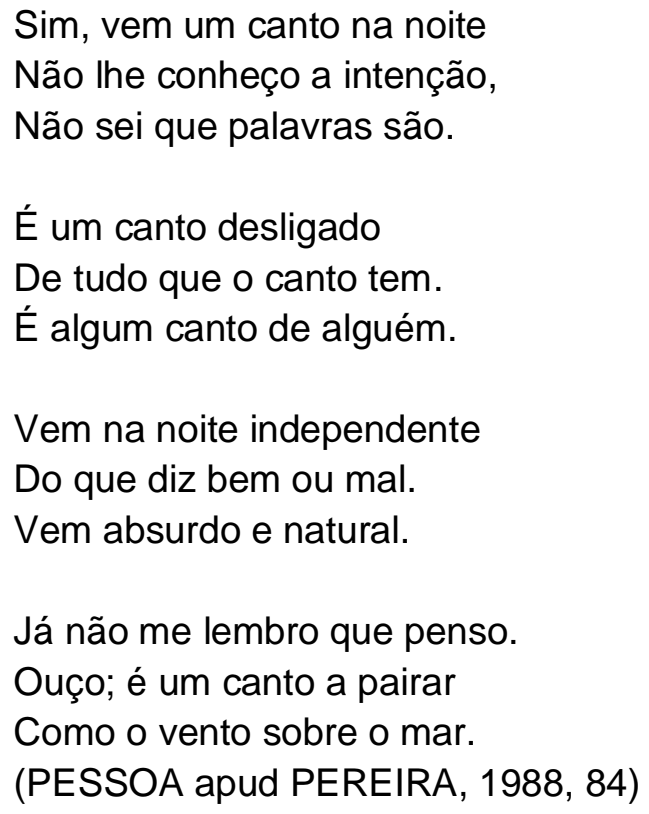

\section{Referências bibliográficas}

APERGHIS, Georges. Le corps musical. Arles: Acte Sud, 1990.

BERGSON, Henri. [1939] Matéria e memória, tr. br. Paulo Neves. São Paulo: Martins Fontes, 1999. (Matière et mémoire. Paris: PUF, 1939).

BIRAN, Maine de. [1807] De l'aperception immédiate. Paris: Libraire Générale Française, 2005.

BORGES, Jorge Luis. [1995] Borges Oral \& Sete Noites. São Paulo: Cia. das Letras, 2011.

BRELET, Gisèle. Le temps musical: essai d'une esthétique nouvelle de la musique. Paris: PUF, 1949.

. L'interprétation créatrice. Paris: PUF, 1951.

CALVINO, Italo. [1983] Palomar, tr. br. Ivo Barroso. São Paulo: Cia. das Letras, 2010. 


\section{Criaçäo \&}

CHION, Michel. Guide des objets sonores: Pierre Schaeffer et la recherche musicale. Paris: Buchet/Chastel, 1983.

COSTA MALUFE, Annita. "Estilo e repetição: Deleuze e algumas poéticas contemporâneas". In: Cadernos de Letras, no. 26. Rio de Janeiro, UFRJ, 2010

COX, Arnie. Embodying music: principles of the mimetic hypothesis. Music Theory Online, v. 17, n. 2. Bloomington: Society for Music Theory, 2011.

Scietiae 5, ํㅡㄴ 2, 195-209.

"The Mimetic Hypothesis and Embodied Musical Meaning." In: Musicae

CUNHA, Antônio Geraldo da. [1982] Dicionário etimológico da língua portuguesa. Rio de Janeiro: Lexicon, 2007.

DELEUZE, Gilles [1981]. Espinosa - filosofia prática, tr. Daniel Lins e Fabien Pascal Lins. São Paulo: Escuta, 2002

. [1993] Crítica e clínica, tr. br. Peter Pál Pelbart. São Paulo: Ed. 34, 1997.

. L'abecedaire de Gilles Deleuze, entrevista a Claire Parnet. Paris: Video Edition Montparnasse, 1996.

DELEUZE, Gilles; GUATTARI, Félix. [1980] Mil Platôs - capitalismo e esquizofrenia 2, v. 1, tr. br. Aurélio Guerra Neto e Celia Pinto Costa. São Paulo: Ed. 34, 1995a, p. 22.

. [1980] Mil Platôs - capitalismo e esquizofrenia 2, v. 2. Tr. Br. Ana Lúcia de Oliveira e Lúcia Cláudia Leão. São Paulo: Ed. 34, 1995b.

. [1980] Mil Platôs - capitalismo e esquizofrenia 2, v. 3, tr. br. Ana Lúcia de Oliveira e Lúcia Cláudia Leão. São Paulo: Ed. 34, 1996

. [1980] Mil platôs - capitalismo e esquizofrenia 2, v. 4, tr. br. Suely Rolnik. Rio de Janeiro: Éd. 34, 1997a.

. [1980] Mil platôs - capitalismo e esquizofrenia 2, v. 5, tr. br. Peter Pál Pelbart e Janice Caiafa. Rio de Janeiro: Éd. 34, 1997b.

[1972/1973] O Anti-Édipo, tr. br. Luiz B. L. Orlandi. São Paulo: Ed. 34, 2010.

ESPINOSA, Baruch de. [1677] Ética: demonstração à maneira dos geometras. Coleção Os Pensadores, volume II, tr. br. Joaquim de Carvalho, Joaquim Ferreira Gomes, Antônio Simões. São Paulo. Nova Cultura, 1989.

FERRAZ, Silvio. [2005] Livro das sonoridades [notas dispersas sobre composição]. $2^{\underline{a}}$ Edição. Rio de Janeiro, 7Letras, 2018.

FOWLER, Carol A.; GALANTUCCI, Bruno; Turvey, M. T. "The motor theory of speech perception reviewed”, In: Psychon Bull Rev, vol. 13, no 3. 2006, pp. 361-377.

GODINHO Ana. Linhas do estilo - estética e ontologia em Gilles Deleuze. Lisboa: Relógio d'Água, 2007. 


\section{Criação \&}

GUATTARI, Félix. [1990] “À propos des machines”. In: Qu'est-ce que l'écosophie?. Paris: Éd lignes/imec, 2013, 111-129.

GUIMARÃES ROSA, João. Sagarana. Rio de Janeiro: Nova Fronteira, 2001a [1946].

LIGETI, György. [1966] “Aventures et Nouvelles Aventures”, In: L'atelier du compositeur. Tr. Fr. Catherine Fourcassié, Pierre Michel et al. Genebra: Contrechamps, 2013.

LINS, Daniel. "Deleuze: o surfista da imanência". In: LINS, Daniel; GIL, José. Nietzsche / Deleuze: Jogo e Música. Rio de Janeiro, Fortaleza: Forense, Fundação de Cultura, Esporte e Turismo, 2008, 53-75.

NIETZSCHE, Friedrich. [1887]. A genealogia da moral. São Paulo, Escala, 2007.

ORLANDI, Luiz B. L. “Um gosto pelos encontros”, In: Arrastões na imanência. Campinas: Phi, 2018, 395-417.

PENHA, Gustavo. Entre escutas e solfejos: afetos e reescrita crítica na composição musical. Tese (Doutorado), Instituto de Artes, Universidade Estadual de Campinas, Campinas, 2016.

Unespar, 2019, pp. 1-29.

. "Música e a produção de afetos". In: Revista Vórtex, vol. 7, №1. Curitiba:

PEREIRA, Kleide F. A. A obsessão da música na poesia de Fernando Pessoa. Rio de Janeiro: UFRJ, 1988.

SAUVAGNARGUES, Anne. "Deleuze, cartografias do estilo: assignificante, intensivo, impessoal”. In Artefilosofia, no 9. Ouro Preto: UFOP, 2010, pp 20-34.

SCHAEFFER, Pierre. Traité des objets musicaux: essai interdisciplines. Paris: Seuil, 1966.

SMITH, J. David; WILSON, Margaret; REISBERG, Daniel. "The role of subvocalization in Auditory Imagery”. In: Neuropsychologia, vol. 33, no 11. Elsevier Science, 1995, pp. 14331454.

SOURIS, André. [1958-1961] "Sur quelques termes fondamentaux du vocabulaire musical". In: Conditions de la Musique et autres écrits. Bruxelas, Paris: Ed. de l'Université de Bruxelles, Éditions du Centre National de la Recherche Scientifique, 1976, pp. 248-266.

ZOURABICHVILLI, François. [2004] Deleuze: uma filosofia do acontecimento. Tr, Br, Luiz B. L. Orlandi. São Paulo: Ed. 34, 2016. Le vocabulaire de Deleuze. Paris, Ellipses, 2003.

Recebido em: 30/08/2021

Aceito em: 24/11/2021

Referência eletrônica: PENHA, Gustavo Rodrigues. Ouvido-voz: uma máquina. Criação \& Crítica, n. 31, p., dez. 2021. Disponível em: $<$ http://revistas.usp.br/criacaoecritica>. Acesso em: dd mmm. 